\title{
Basic Amino Acid Residues of Human Eosinophil Derived Neurotoxin Essential for Glycosaminoglycan Binding
}

\section{Ta-Jen Hung ${ }^{1}$, Wei-Tang Chang ${ }^{1}$, Noboru Tomiya ${ }^{2}$, Yuan-Chuan Lee ${ }^{1,2}$, Hao-Teng Chang ${ }^{3}$, Chien-Jung Chen ${ }^{1}$, Ping-Hsueh Kuo ${ }^{1}$, Tan-chi Fan ${ }^{4}$ and Margaret Dah-Tsyr Chang ${ }^{1,5, *}$}

1 Institute of Molecular and Cellular Biology, National Tsing Hua University, Hsinchu 300, Taiwan; E-Mails: d9680804@oz.nthu.edu.tw (T.-J.H.); extraby123@nhri.org.tw (W.-T.C.); ylee7@jhu.edu (Y.-C.L.); iverson13179@hotmail.com (C.-J.C.); s9980584@m99.nthu.edu.tw (P.-H.K.)

2 Department of Biology, Johns Hopkins University, Baltimore, MD 21218, USA; E-Mail: ntomiya1@jhu.edu

3 Graduate Institute of Basic Medical Science, China Medical University, Taichung 404, Taiwan; E-Mail: htchang@mail.cmu.edu.tw

4 Stem Cell and Translational Cancer Research Center, Chang Gung Memorial Hospital at Linkou, Taoyuan 333, Taiwan; E-Mail: tcf@gate.sinica.edu.tw

5 Department of Medical Science, National Tsing Hua University, Hsinchu 300, Taiwan

* Author to whom correspondence should be addressed; E-Mail: dtchang@life.nthu.edu.tw; Tel.: +886-3-574-2463; Fax: +886-3-571-5934.

Received: 15 August 2013; in revised form: 6 September 2013 / Accepted: 11 September 2013 / Published: 16 September 2013

\begin{abstract}
Human eosinophil derived neurotoxin (EDN), a granule protein secreted by activated eosinophils, is a biomarker for asthma in children. EDN belongs to the human RNase A superfamily possessing both ribonucleolytic and antiviral activities. EDN interacts with heparin oligosaccharides and heparin sulfate proteoglycans on bronchial epithelial Beas-2B cells. In this study, we demonstrate that the binding of EDN to cells requires cell surface glycosaminoglycans (GAGs), and the binding strength between EDN and GAGs depends on the sulfation levels of GAGs. Furthermore, in silico computer modeling and in vitro binding assays suggest critical roles for the following basic amino acids located within heparin binding regions (HBRs) of EDN ${ }^{34} \mathrm{QRRCKN}^{39}$ (HBR1), ${ }^{65} \mathrm{NKTRKN}^{70}$ (HBR2), and ${ }^{113} \mathrm{NRDQRRD}{ }^{119}$ (HBR3) and in particular $\mathrm{Arg}^{35}, \mathrm{Arg}^{36}$, and $\mathrm{Arg}^{38}$ within HBR1, and $\mathrm{Arg}^{114}$ and $\mathrm{Arg}^{117}$ within HBR3. Our data suggest that sulfated GAGs play a major role in EDN binding, which in turn may be related to the cellular effects of EDN.
\end{abstract}


Keywords: eosinophil derived neurotoxin; heparin; glycosaminoglycan; heparin binding region

Abbreviations: AMAC, 2-aminoacridone; $\mathrm{CHO}$, Chinese hamster ovary; CS, chondroitin sulfate; CSA, chondroitin sulfate A; CSB, chondroitin sulfate B; CSC, chondroitin sulfate C; DC, dendritic cell; $\mathrm{DS}$, dermatan sulfate; de2O-SH, de-2-O-sulfated heparin; de6O-SH, de-6-O-sulfated heparin; $d e N-\mathrm{SH}$, de- $N$-sulfated heparin; ECP, eosinophil cationic protein; EDN, eosinophil derived neurotoxin; FACE, fluorescence-assisted carbohydrate electrophoresis; FGF, fibroblast growth factor; GAG, glycosaminoglycan; HS, heparan sulfate; HBR, heparin binding region; HMWH, high molecular weight heparin; HRP, horseradish peroxidase; HIV, human immunodeficiency virus; hRSV, human respiratory syncytial virus; HA, hyaluronic acid; LMWH, low molecular weight heparin; $\mathrm{MBP}$, Maltose-binding protein; $\mathrm{NAc}-\mathrm{deO}$-SH, $\mathrm{N}$-acetyl-de- $\mathrm{O}$-sulfated heparin; TLR2, toll-like receptor 2; NAcH, N-acetyl heparin; PFA, paraformaldehyde; SD, standard deviation; mEAR, mouse eosinophil-associated RNase; Th2, Type 2 helper T cell.

\section{Introduction}

Human eosinophil derived neurotoxin (EDN) is a basic protein ( $\mathrm{pI}$ 8.9) normally stored in cytoplasmic granules and secreted by activated eosinophilic leukocytes [1]. It is also found in basophils, neutrophils, mononuclear cells and organs associated with these types of white blood cells [2-4]. EDN was initially discovered as a neurotoxin with selective killing effects on cerebellar Purkinje cells [5] and later on classified as a member of the RNase A superfamily [6]. It induces Gordon phenomenon which shows muscle stiffness, ataxia, incoordination, and spasmodic paralysis in animal models [1,7]. EDN shows in vitro antiviral activity against RNA viruses, including human respiratory syncytial virus (hRSV), para-influenza virus [8], and human immunodeficiency virus (HIV)-1 [9,10]. Furthermore, recent studies have reported that EDN can be used as a biomarker of eosinophilic esophagitis [11] and amyotrophic lateral sclerosis [12].

EDN and its mouse counterpart, mouse eosinophil-associated RNase 2 (mEAR2), have been reported to act as a selective chemoattractant for dendritic cells (DCs) [13]. They promote activation and maturation of DCs [14] and augment Type 2 helper T cell (Th2)-biased immune responses in a toll-like receptor 2 (TLR2)-dependent manner [15]. TLR2 is expressed on the surface of a wide variety of cells including lung bronchial epithelial cells [16] as well as microglial cells [17] and immune cells, such as DCs and macrophages [18]. Our previous study [19] showed that maltose-binding protein fused EDN (MBP-EDN) could interact with Beas-2B cells, a human bronchial epithelial cell line with limited expression of transcripts of TLR2 gene [16]. It suggested that MBP-EDN might interact with other components (other than TLR2) on cell surface of Beas-2B cells.

EDN shows affinity for heparin, as indicated by its purification in 1986 using heparin-Sepharose column chromatography [20]. We have recently found that heparin oligosaccharides added exogenously inhibit the interaction between EDN and Beas-2B cells [19]. Our data suggested that EDN bound not only heparin used in in vitro experiments, but also heparan sulfate (HS) expressed on the surface of Beas-2B cells. Heparin and HS are linear polysaccharides consisting of repeating disaccharide units of 
$\alpha-1,4-$ linked hexuronic acid and hexosamine [21]. The hexuronic residues typically consist of $90 \%$ IdoA and $10 \%$ GlcA [22]. Most common disaccharide units of heparin contain 2-O-sulfated IdoA and 6-O- and $\mathrm{N}$-sulfated GlcN [23]. In addition to HS, other GAGs such as chondroitin sulfate (CS), dermatan sulfate (DS), and hyaluronic acid (HA) are also present on the cell surface as well as in extracellular matrix [21]. These GAGs have been shown to interact with numerous proteins including cytokines, growth factors, and proteases to modulate functions of proteins, and are implicated in many biological processes including cell growth, development, immunology, and disease processes [24,25].

It is empirically known that heparin binding proteins have domains characterized by the presence of clusters of positively charged residues, such as Arg and Lys, which are likely to promote heparin binding by electrostatic interactions [26]. Two conventional heparin binding sequences, XBBXBX or $\mathrm{XBBBXXBX}$ ( $\mathrm{X}$ is a hydrophobic or uncharged amino acid, and $\mathrm{B}$ is a basic amino acid) were classified by sequence comparison of various heparin binding proteins [27]. The amino acid sequence of EDN contains 12 basic amino acids ( 8 Arg and 4 Lys residues), and nine of them are concentrated within three regions including ${ }^{34} \mathrm{QRRCKN}^{39}$ in loop $3,{ }^{65} \mathrm{NKTRKN}^{70}$ in loop 4, and ${ }^{113} \mathrm{NRDQRRD}^{119}$ in loop 7 [20]. All of these regions have three basic amino acids in contiguous five residues. Among which the sequence pattern ${ }^{34} \mathrm{QRRCKN}{ }^{39}$ matches exactly to the XBBXBX motif [28], and indeed a 10-amino acid peptide, ${ }^{32} \mathrm{NYQRRCKNQN}{ }^{41}$, has been demonstrated to be capable of binding heparin [29]. Regarding the other two regions, ${ }^{65} \mathrm{NKTRKN}^{70}$ also possesses the XBBXBX pattern in a reverse order, but ${ }^{113} \mathrm{NRDQRRD}{ }^{119}$ does not have any known heparin binding sequence. To date, the second and the third regions serving as binding sites for heparin in EDN have not been described.

In this study, the sequences ${ }^{34} \mathrm{QRRCKN}^{39},{ }^{65} \mathrm{NKTRKN}^{70}$ and ${ }^{113} \mathrm{NRDQRRD}^{119}$ were identified as heparin binding regions (HBRs) - i.e., HBR1, HBR2 and HBR3, respectively-and their functional roles in heparin binding were characterized using in silico computer modeling and in vitro binding assays. Furthermore, the importance of sulfo groups of GAGs in interaction with EDN was characterized.

\section{Results and Discussion}

\subsection{Binding of MBP-EDN to Heparin and Beas-2B Cells}

Neuton D. L. et al. [30] have expressed EDN without any tag, and recovered recombinant EDN from inclusion bodies through denaturation, renaturation, dialysis, and repeating purification steps by heparin-Sepharose column and a Sephadex G100 column chromatography. Although untagged, recombinant EDN can be produced by established procedures above; refolding under an artificial condition with low yield makes it time consuming for intensive assay. Producing a protein soluble in host bacteria is a general strategy recombinant protein technology. Thus, to increase protein solubility and recovery yield of recombinant EDN, here we fused MBP tag at $N$-terminus. Nevertheless, potential influence of bulky MBP tag in EDN function by blocking GAG binding sites would be further evaluated. 
Figure 1. Maltose-binding protein-eosinophil derived neurotoxin (MBP-EDN) binding to low molecular weight heparin (LMWH) and Beas-2B cells. (A) 2-aminoacridone (AMAC)-labeled LMWH $(0.33 \mathrm{nmol})$ was incubated with or without MBP-EDN (protein: LMWH ratio of 0.4 to 2.5) in PBS at $25{ }^{\circ} \mathrm{C}$ for $15 \mathrm{~min}$, and the reaction products were separated by gel electrophoresis using 1\% agarose gel. The probe and protein were indicated at the top of the gel, and the numbers shown at the bottom of the gel indicate the relative intensity (\%) of free probe and the molar ratios of protein to LMWH. FP, free probe; BP, bound probe; (B) Beas-2B cells were treated with indicated MBP-EDN/MBP concentrations in RPMI 1640 medium at $4{ }^{\circ} \mathrm{C}$ for $1 \mathrm{~h}$. The levels of bound proteins were determined by cELISA. The amount of MBP-EDN (a positive control) bound to Beas-2B cells at $0.8 \mu \mathrm{M}$ was set to $100 \%$, and MBP was used as negative control. The data shown are mean \pm SD in triplicate assays.

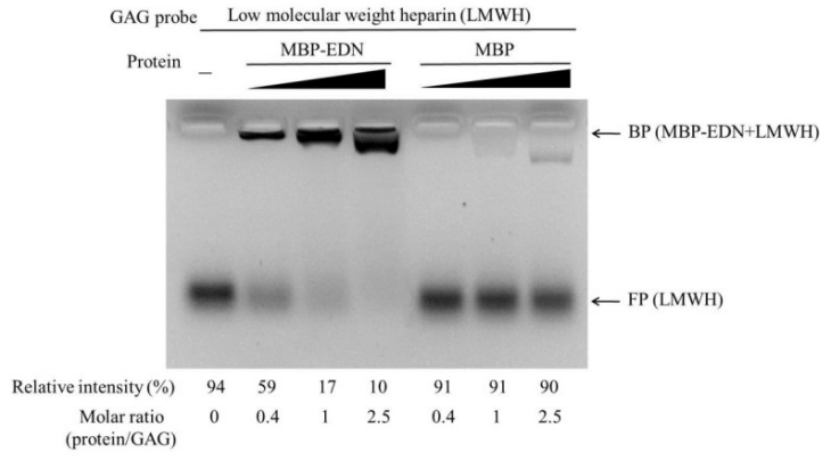

(A)

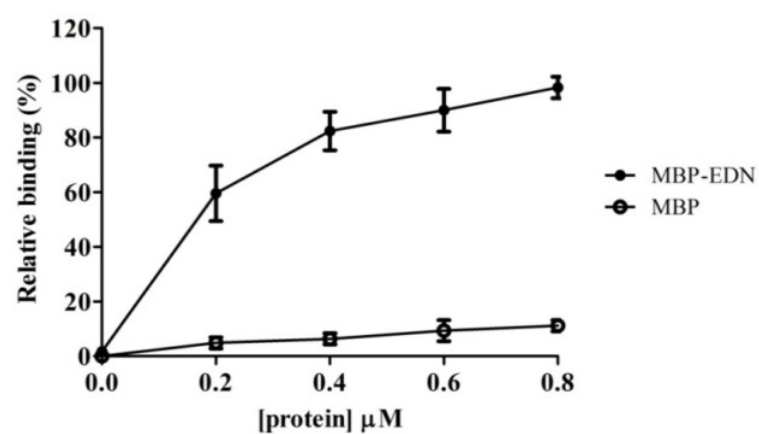

(B)

Binding of recombinant MBP-EDN to heparin and Beas-2B cells was characterized by FACE and cELISA [28]. In the former case, purified MBP-EDN was incubated with 2-aminoacridone-labeled low molecular weight heparin (AMAC-LMWH) at different molar ratios, and the samples were subjected to gel electrophoresis on a $1 \%$ agarose gel plate to separate MBP-EDN bound AMAC-LMWH and free polysaccharide. Figure 1A showed that AMAC-LMWH signal shifted upon addition of increasing molar ratio of MBP-EDN over AMAC-LMWH, and 90\% signal shifted at a MBP-EDN: AMAC-LMWH ratio of 2.5. In a control experiment, at the same ratio of protein $v$ s. AMAC-LMWH, only $10 \% \mathrm{MBP}$ appeared as a complex with AMAC-LMWH. Concentration-dependent binding of MBP-EDN to Beas-2B cells was also observed by cELISA. MBP showed only a background level of signals (11\%), compared to that of MBP-EDN (100\%) at $0.8 \mu \mathrm{M}$ (Figure 1B). These data clearly indicate that binding of MBP-EDN to both LMWH and Beas-2B cells is mediated by the EDN moiety, but not the MBP moiety, of the fusion protein used in this study.

To further differentiate differences in GAG binding affinity between MBP-EDN and refolded recombinant EDN (EDN-6His), heparin binding activity of both was measure as shown in Figure S1. Approximately an $83 \%$ shift at 1 molar ratio of protein to glycan suggested that our MBP-EDN (Figure 1A) possessed comparable heparin binding activity to refolded EDN-6His (88\% shift) (Figure S1), strongly indicating that MBP tag may not influence ligand binding property of EDN. Our observation was consistent with other studies demonstrating that the MBP tagged proteins such as 
MBP-tagged eosinophil cationic protein (MBP-ECP) [31] and dengue virus envelope protein [32] still remained GAG binding affinities.

\subsection{Involvement of Cell Surface GAGs in Binding to MBP-EDN}

Interaction of MBP-EDN with cell surface GAGs was further investigated using wild type Chinese hamster ovary $(\mathrm{CHO})$ cell line (CHO-K1) [33], and two mutant cell lines with specific defects in proteoglycan biosynthesis. Both $\mathrm{CHO}-\mathrm{K} 1$ cells and the two mutant $\mathrm{CHO}$ cells showed a dose-dependent binding between 0 and $0.8 \mu \mathrm{M}$ of MBP-EDN (Figure 2A). Under similar conditions, MBP itself showed negligible levels (less than 10\% activity of MBP-EDN) of binding in all three cell lines (Figure 2A).

Figure 2. Involvement of glycosaminoglycans (GAGs) on cell surface in binding to MBP-EDN. (A) Chinese hamster ovary (CHO)-K1 (control), pgsD-667 (HS-deficient) and pgsA-745 (GAG-deficient) cells were treated with MBP-EDN/MBP at indicated concentrations in Vitacel Ham's F12K medium supplemented with $10 \%$ FBS at $4{ }^{\circ} \mathrm{C}$ for $1 \mathrm{~h}$. The amount of $0.8 \mu \mathrm{M}$ MBP-EDN bound to CHO-K1 cell was set to $100 \%$ and MBP was used as a negative control; (B) Relative binding activity of each protein at $0.8 \mu \mathrm{M}$. The data shown are mean $\pm \mathrm{SD}$ in triplicate assays. ${ }^{* * *}, p<0.001$.

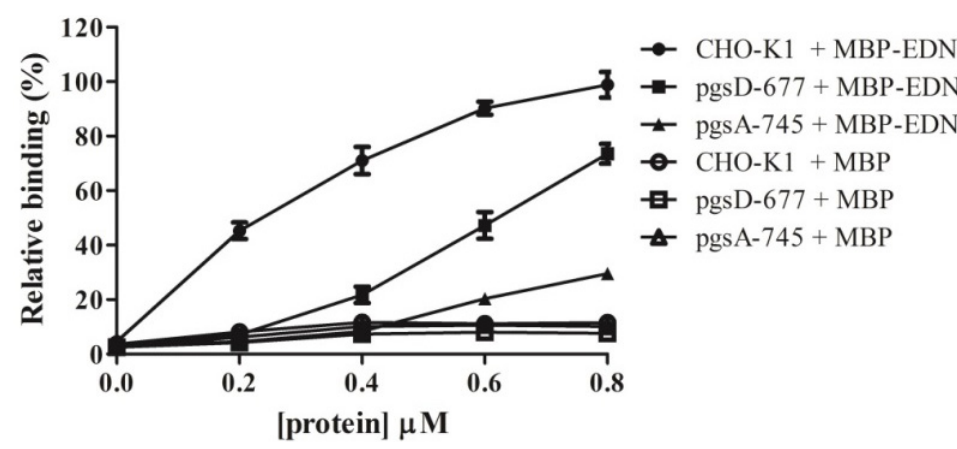

(A)

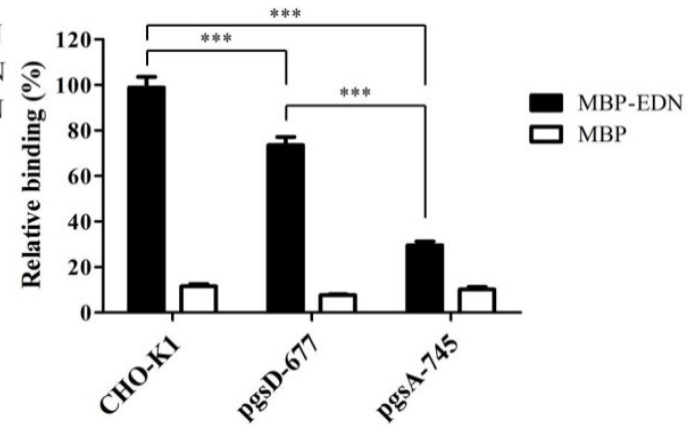

(B)

In the mutant $\mathrm{CHO}$ cell line pgsD-677, synthesis of HS is specifically impaired due to lack of HS polymerase that polymerizes disaccharide units of outer HS chains. However, pgsD-677 cells have approximately three times more CS as compared to CHO-K1 cells [34]. The amount of MBP-EDN bound to pgsD-677 cells is reduced by $26 \%$ (at $0.8 \mu \mathrm{M}$ ) as compared to that of CHO-K1 cells (Figure 2B), indicating that cell surface HS is at least partially responsible for binding of EDN. The pgsA-745 cell line expresses less than 5\% of the GAGs expressed by CHO-K1 cells due to the lack of a xylosyltransferase which catalyzes the first step in biosynthesis of GAG [35]. As shown in Figure 2B, the amounts of MBP-EDN bound to pgsA-745 cells significantly reduced by $71 \%$ as compared to CHO-K1 cells. The level of bound MBP-EDN to pgsD-677 cells was significantly reduced than that of pgsA-745 cells, suggesting that cell surface GAGs other than HS may be also involved in the interaction between MBP-EDN and CHO-K1 cells.

To further investigate specificity of MBP-EDN binding, we measured the inhibitory activity of different types of GAGs including high molecular weight heparin (HMWH) which is highly sulfated, chondroitin sulfate $\mathrm{C}$ (CSC) and dermatan sulfate (DS) which are moderately sulfated compared to HMWH, and hyaluronic acid (HA). Among these four GAGs, HMWH showed a high level of inhibition 
(87\%) compared with the binding of LMWH to MBP-EDN, and DS reduced LMWH binding by 50\% at a GAG: LMWH ratio of 5. However, the same amount of CSC and HA had no effect (Figure 3A). Similar results were obtained by cELISA competition assays (Figure 3B). HMWH and DS significantly reduced MBP-EDN binding to Beas-2B cells in a dose-dependent manner. At a concentration of $10 \mu \mathrm{g} / \mathrm{mL}, \mathrm{HMWH}$ and DS reduced MBP-EDN binding to the cells by $79 \%$ and $54 \%$, respectively. However, CSC and HA had no effect. At $50 \mu \mathrm{g} / \mathrm{mL}$, both $\mathrm{HMWH}$ and DS showed over $80 \%$ of inhibitory effects, whereas CSC manifested only $20 \%$ inhibition, and HA did not affect MBP-EDN binding. These data suggest that EDN has a higher affinity to heparin/HS and DS than to other types of GAGs.

Figure 3. Ligand specificity of major GAGs for interacting with MBP-EDN. (A) AMAC-labeled LMWH $(0.33 \mathrm{nmol})$ was pre-incubated with five-fold molar excess of unlabeled GAGs at $25^{\circ} \mathrm{C}$ for $5 \mathrm{~min}$, and then incubated with or without MBP-EDN (equal molar ratio) in PBS at $25{ }^{\circ} \mathrm{C}$ for $15 \mathrm{~min}$. The reaction products were separated by gel electrophoresis using 1\% agarose gel. The amount of AMAC-LMWH without any treatment was set to $100 \%$. Relative intensity (\%) of free probe and unlabeled competitors are indicated at the bottom of the gel image. FP, free probe; BP, bound probe; (B) Beas-2B cells were pre-incubated with various GAGs in RPMI 1640 medium at $4{ }^{\circ} \mathrm{C}$ for 30 min before treatment with $5 \mu \mathrm{g} / \mathrm{mL}$ of MBP-EDN at $4{ }^{\circ} \mathrm{C}$ for an additional $1 \mathrm{~h}$. The levels of bound MBP-EDN/MBP were determined by cELISA. The amount of MBP-EDN bound to Beas-2B cells without GAG treatment was set to $100 \%$. C, control. The data shown are mean $\pm \mathrm{SD}$ in triplicate assays. ${ }^{* *}, p<0.01 ; * * *, p<0.001$.

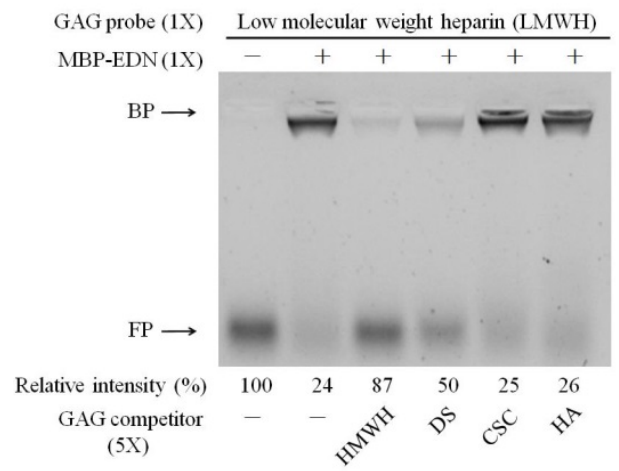

(A)

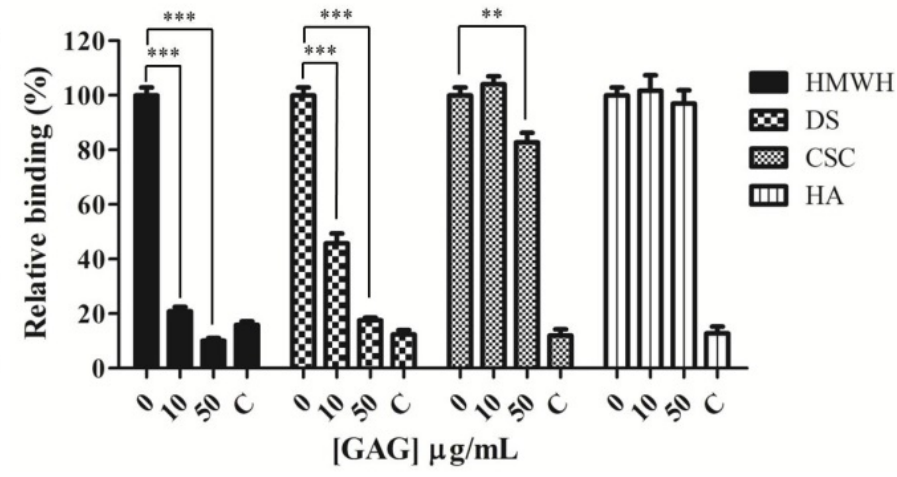

(B)

HMWH, the most sulfated GAG containing on average 2.7 sulfo groups per disaccharide unit, possessed higher inhibitory activity than DS and CSC that have one sulfo group per disaccharide unit as expected (Figure 3). However, DS and CSC sharing similar sulfation levels showed distinctly different results, indicating that the sugar moieties and other factors were also involved in EDN-GAG interaction. DS has been named as chondroitin sulfate B (CSB) since it has an $N$-acetylgalactosamine (GalNAc), and is distinguishable from chondroitin sulfate A (CSA) (4-O-sulfated) and CSC (6- $O$-sulfated) mainly in the presence of IdoA moiety which also appears in heparin/HS [36]. Since there are many functional similarities between DS and HS, and some GAG binding proteins bind both DS and HS [37], IdoA moiety seems to play an important role in binding specificity for GAG binding protein. The importance 
of IdoA in hepatocyte growth factor/scatter factor GAG interaction has been shown before [38]. Cell surface GAGs containing IdoA are also required for efficient hRSV infection [39]. These reports support the involvement of the IdoA moiety in EDN-heparin interactions. On the other hand, disaccharide units of both heparin/HS and HA contain Glc $N$ in common, in contrast to Gal $N$ in DS and CSC. However, the inhibitory activity of HA was very low. These data discount the possibility of the Glc $N$ moiety being involved in EDN-GAG interactions.

Many biological activities attributable to EDN and ECP have been characterized and found to be significantly different; nevertheless, EDN and ECP still present similar properties such as ribonucleolytic [40], antiviral [41], and heparin/HS binding activities [28]. Cell surface GAG binding selectivity of ECP has been demonstrated with similar protocol [31]. In addition, binding affinities of ECP to various GAG disaccharides were also predicted by docking simulation [42], showing that ECP had a higher affinity to interact with heparin rather than HA or CSC. Interestingly, HA had a higher inhibitory effect and binding affinity than CSC in these studies, implying that electrostatic interactions were not the only factor involved in EDN/ECP-GAG interactions and the difference in GAG recognition mode between EDN and ECP might arise from diverse biological functions of these two eosinophil RNases.

\subsection{Requirement of Sulfo Groups on Heparin for Binding to EDN}

The sulfo groups of heparin/HS are important for biological functions including fibroblast growth factor (FGF) signaling [43] and virus infection $[44,45]$. We tested the effects of sulfo groups of heparin on EDN binding, using intact, untreated HMWH and heparin derivatives: $N$-acetyl heparin $(N A c H)$, $d e-N$-sulfated heparin ( $d e N$-SH), $N$-acetyl-de-O-sulfated heparin ( $N A c-d e O-\mathrm{SH}$ ), de-2-O-sulfated heparin $(d e 2 O-\mathrm{SH})$, and de-6-O-sulfated heparin $(d e 6 O-\mathrm{SH})$. Figure $4 \mathrm{~A}$ shows that among these compounds HMWH inhibited binding of LMWH to MBP-EDN most effectively ( $89 \%$ inhibition). In contrast, $N A c-d e O-S H$ (completely devoid of $O$-sulfo group and with a markedly diminished $N$-sulfation) showed the weakest inhibition (2\%) of MBP-EDN binding to AMAC-LMWH, indicating that the sulfo groups provided almost all necessary negative charges for binding to EDN. Four other derivatives with selectively modified sulfo groups including $\mathrm{NAcH}$, deN-SH, de $2 O-\mathrm{SH}$, and $d e 6 O-\mathrm{SH}$ showed $31 \%, 8 \%, 43 \%$, and $39 \%$ inhibition activities, respectively. Similarly, results of cELISA competition assay revealed that HMWH inhibited $87 \%$ of cellular binding of MBP-EDN while $\mathrm{NAc}-\mathrm{deO}$-SH showed only $7 \%$ inhibitory effect at a concentration of $10 \mu \mathrm{g} / \mathrm{mL}$. Regarding other derivatives, deN-SH, $\mathrm{NAcH}$, de2O-SH, and de6O-SH showed 34\%,69\%, 66\% and 70\% inhibition activities at the same concentration, respectively, compared with the control without competitor. At $50 \mu \mathrm{g} / \mathrm{mL}$, all heparin derivatives showed more than 50\% inhibition whereas $N A c-d e O-S H$ inhibited only $24 \%$ (Figure 4B).

Although heparin lacking of 2-O- or 6-O-sulfo groups showed a decreased MBP-EDN binding activity, it could not completely abolish the interaction between MBP-EDN and Beas-2B cells. This suggests that EDN might not interact with heparin through only one specific position of sulfo group, unlike FGF-1 or FGF-2, which require 6- $O$ sulfated [46] and 2- $O$ sulfated heparin [47] for interaction. In addition, the 3-O-sulfo group which rarely appears in heparin/HS and has been proposed to be important for interaction with FGF-7 [43] and infection of herpes simplex virus type 1 [44] might also be required 
for interaction with EDN. With respect to $N$-sulfo groups, although both $N A c H$ and $d e-N$-SH were able to significantly reduce MBP-EDN binding to Beas-2B cells, the inhibitory effect of NAcH (69\%) was higher than that of $d e-N-\mathrm{SH}(34 \%)$. Besides, out of these two derivatives, only $N A c H$ was observed to compete with the interaction between LMWH and MBP-EDN by FACE analysis, suggesting that the $\mathrm{N}$-acetyl group of heparin, which appears in most HS sequences, may be responsible for weaker binding to MBP-EDN.

Figure 4. Involvement of heparin sulfo groups in binding to MBP-EDN. (A) AMAC-labeled LMWH (0.33 nmol) was incubated with 10-fold molar excess of unlabeled heparin derivatives, individually, prior to incubation with or without MBP-EDN (equal molar ratio) in PBS at $25{ }^{\circ} \mathrm{C}$ for $15 \mathrm{~min}$. The reaction products were separated by gel electrophoresis on $1 \%$ agarose gels. The amount of AMAC-LMWH without any treatment was set as $100 \%$. Relative intensity (\%) of free probe and unlabeled competitors are indicated at the bottom of the gel image. FP, free probe; BP, bound probe; (B) Beas-2B cells were pre-incubated with different heparin derivatives in RPMI 1640 medium at $4{ }^{\circ} \mathrm{C}$ for 30 min before treatment with $5 \mu \mathrm{g} / \mathrm{mL}$ of MBP-EDN at $4{ }^{\circ} \mathrm{C}$ for an additional $1 \mathrm{~h}$. The levels of bound proteins were determined by cELISA, and the amount of MBP-EDN bound to Beas-2B cells pretreatment with no heparin/heparin derivative was set as $100 \%$. C, control. The data shown are mean $\pm \mathrm{SD}$ in triplicate assays. $* * *, p<0.001$.

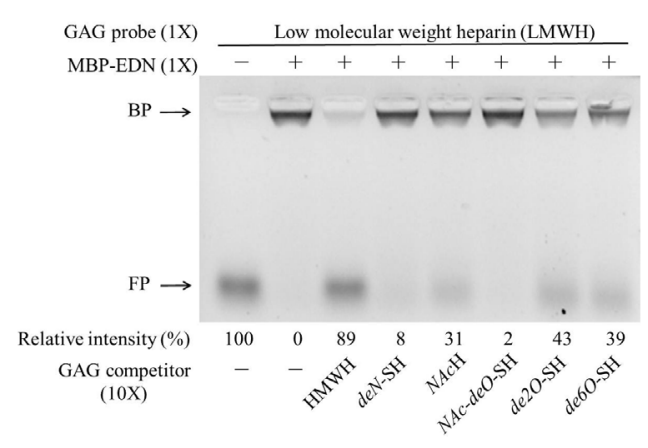

(A)

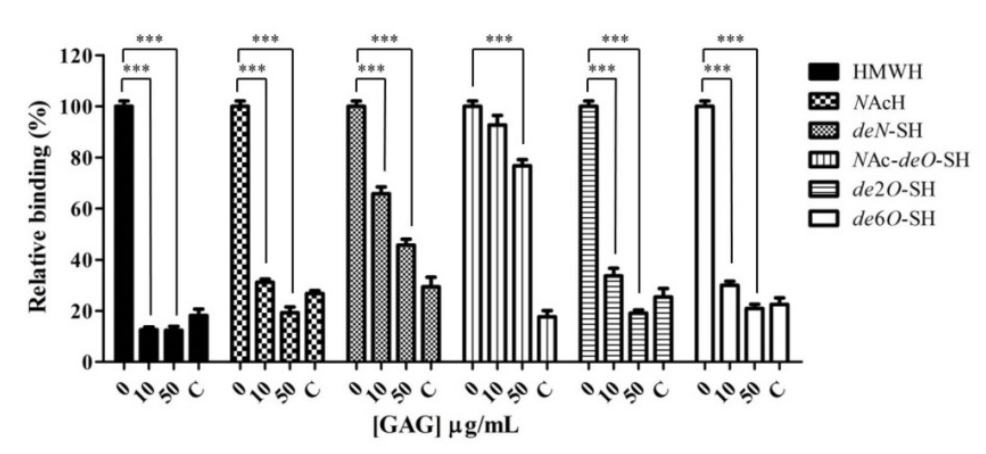

(B)

\subsection{Identification of Critical Basic Residues on EDN for Interaction with Heparin and Other Cell Surface $G A G$}

Minimal length of heparin molecule required for inhibition of MBP-EDN/ECP cellular binding activity has been demonstrated [19,28]. With increasing oligosaccharide length, the degree of MBP-EDN/ECP cellular binding decreased and pentasaccharide served as the minimal length to inhibit cellular binding activities of these proteins. Since $90 \%$ of cellular binding activity of EDN was inhibited by $10 \mu \mathrm{g} / \mathrm{mL}$ heptasaccharide [19], we proposed that heptasaccharide was required for efficient interaction with MBP-EDN. It should be noted that heptasaccharide contained a matrix sugar at the reducing end in the study, suggesting that heparin hexasaccharide might be a suitable length for exerting molecular interaction between EDN and heparin molecule. Thus, heparin hexasaccharide was used to perform computer modeling for EDN-heparin hexasaccharide complex structure and identification of potential binding poses and residues on EDN involved in heparin binding. The molecular surface of 
EDN shows a V-shaped cleft. This cleft contains positively charged residues (Figure 5A). HBR1 is one of the surface regions that constitute the cleft, and a part of HBR2 is located on the edge of the cleft. HBR3 is not a part of the cleft but it was located on the same side of the molecular surface as HBR1 and HBR2. Our model suggests that the bound heparin hexasaccharide was stabilized by ionic interactions with $\mathrm{Arg}^{36}$ and $\mathrm{Lys}^{38}$ in HBR1, and Lys ${ }^{1}$ and $\mathrm{Arg}^{132}$ which did not belong to HBRs, whereas Arg ${ }^{97}$ and basic residues in HBR2 and HBR3 were not located within van der Waals force/hydrogen bond distances to interact with the heparin hexasaccharide (Figure 5B). Other than electrostatic interactions, heparin hexasaccharide also showed potential interactions with EDN by mainly van der Waals (vDW) force and six hydrogen bonds between sugar backbone and $\mathrm{Lys}^{1}, \mathrm{Trp}^{10}, \mathrm{His}^{15}, \mathrm{Arg}^{36}, \mathrm{Gln}^{40}$ and $\mathrm{Leu}^{130}$ as shown in Figure 5B and Table S1.

Figure 5. Computer modeling of an EDN-heparin hexasaccharide complex. The stick model is used to represent heparin hexasaccharide. (A) Electrostatic potential is mapped onto the solvent-accessible surface of the EDN; a blue color indicates a region of positive potential $(+58 \mathrm{kT} / \mathrm{e})$, red indicates a negative potential $(-58 \mathrm{kT} / \mathrm{e})$, and white indicates a neutral potential; (B) Binding mode of heparin hexasaccharide to EDN with the protein shown in cartoon representation. Selected amino acid side chains of EDN are shown in line representation. The ionic interactions between EDN and heparin are shown in violet dashed lines and hydrogen bonds are shown in yellow dashed lines.

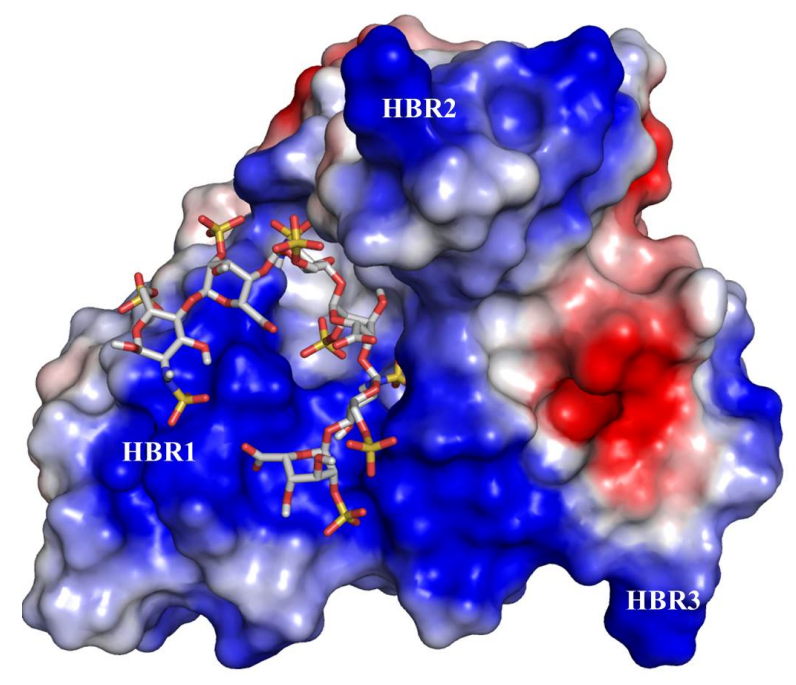

(A)

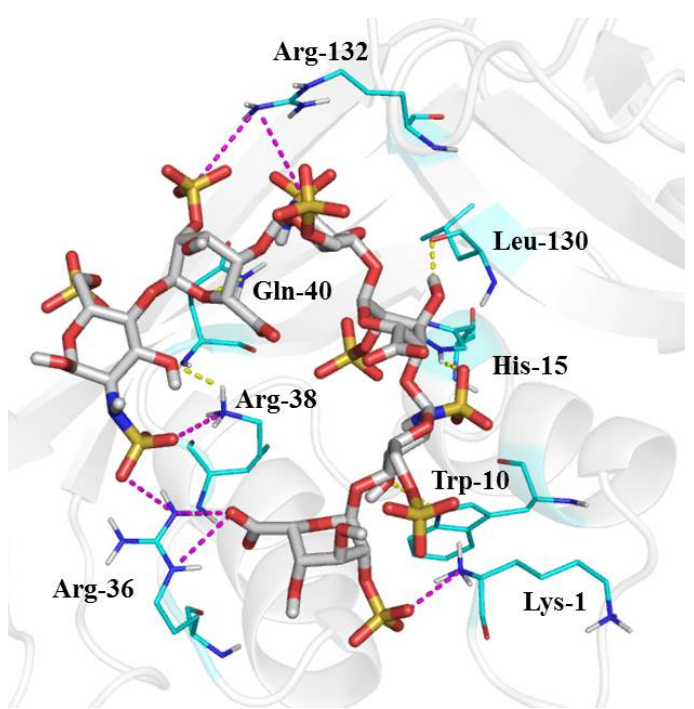

(B)

MBP-EDN-HBR mutants, in which the basic residues in HBRs were replaced with Ala, were generated to investigate the functional roles of HBRs in EDN. All mutants showed a weaker interaction with AMAC-LMWH at different molar ratios of protein/GAG (Figure 6A). The intensity of bound AMAC-LMWH in MBP-EDN, MBP-EDN-HBR1mt (R35A/R36A/K38A), MBP-EDN-HBR2mt (K66A/R68A/K69A), MBP-EDN-HBR3mt (R114A/R117A/R118A), and MBP at equimolar ratios with respect to LMWH were $83 \%, 45 \%, 58 \%, 72 \%$, and $10 \%$, respectively. MBP-EDN-HBR $1 \mathrm{mt}$ at a concentration of $0.2 \mu \mathrm{M}$ also showed only $11 \%$ cellular binding activity, indicating that HBR1, ${ }^{34} \mathrm{QRRCKN}^{39}$, was a key heparin binding motif in EDN. Regarding MBP-EDN-HBR2mt and MBP-EDN-HBR3mt, although their cellular binding activity was reduced to respectively $26 \%$ and $58 \%$ 
at $0.2 \mu \mathrm{M}$ with increasing protein concentration, the cellular binding activity was comparable to that of MBP-EDN (Figure 6B). This suggests that ${ }^{65} \mathrm{NKTRKN}^{70}$ (HBR2) and ${ }^{113} \mathrm{NRDQRRD}^{119}$ (HBR3) play auxiliary roles in the interaction between MBP-EDN and GAGs. Natural heparin is a heterogeneous mixture with molecular weights ranging from $5000 \mathrm{Da}$ to over 40,000 Da (HMWH). LMWHs, in contrast, consist of only short chains of heparin of average molecular weight of less than $8000 \mathrm{Da}$ (approximately 10 disaccharide units). The basic residues of HBR2 and HBR3 which are too far to interact with the heparin hexasaccharide in the computer model might act as a secondary heparin binding sites on EDN and bind with much lower affinity to long chain heparin molecules. Recently, the loop L7 of EDN containing HBR3 has been shown to play an important role in anti-hRSV activity of EDN [48]. Since hRSV infection and hRSV vaccines elicit neutralizing and non-neutralizing antibodies reactive with envelope glycoproteins [49], EDN might recognize specific glycan structures on the virus envelope. Each HBR might be involved in different EDN functions through target selectivity.

Figure 6. Involvement of HBRs on MBP-EDN binding to LMWH and Beas-2B cells. (A) AMAC-labeled LMWH $(0.33 \mathrm{nmol})$ was incubated with each HBR-mutated MBP-EDN (protein: LMWH ratio of 0.4 to 2.5 ) in $\mathrm{PBS}$ at $25{ }^{\circ} \mathrm{C}$ for $15 \mathrm{~min}$, and the reaction products were separated by gel electrophoresis on $1 \%$ agarose gels. Probes and proteins used are indicated at the top of the gel. The amount of AMAC-LMWH without any treatment was set as $100 \%$. The numbers shown at the bottom of the gel images indicate the relative intensity $(\%)$ of free probe and the molar ratios of proteins to LMWH. MBP was used as a negative control. FP, free probe; BP, bound probe; (B) Beas-2B cells were separately treated with $0 \mu \mathrm{M}$ to $0.8 \mu \mathrm{M}$ HBR-mutated MBP-EDN. The levels of bound proteins were determined by cELISA. The amount of MBP-EDN bound to Beas-2B cells at $0.8 \mu \mathrm{M}$ was set as $100 \%$. The data shown are mean \pm SD of triplicate assays.

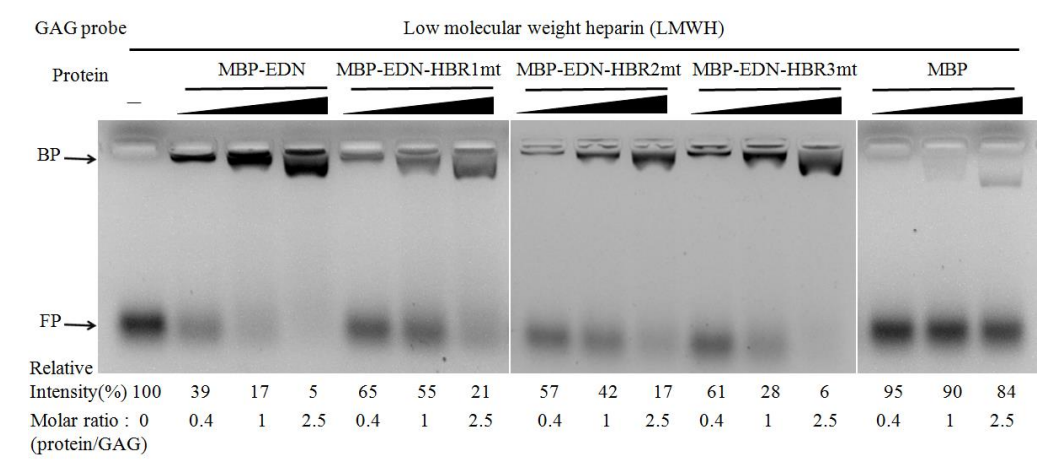

(A)

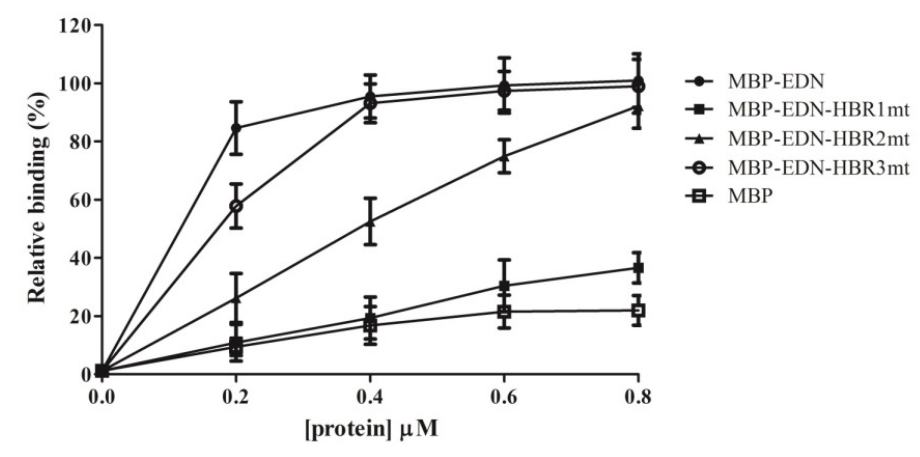

(B) 
Putative HBRs on ECP including ${ }^{34} \mathrm{RWRCK}^{38},{ }^{73} \mathrm{RSRFR}^{77}$, and ${ }^{101} \mathrm{RPGRR}^{105}$ have been aligned with the corresponding segments of the other 12 RNases employing Clustal W2 [50]. Among these three HBRs, only HBR1 on ECP $\left({ }^{34} \mathrm{RWRCK}^{38}\right)$ is found in a position comparable with HBR1 on EDN $\left({ }^{34} \mathrm{QRRCK}^{38}\right)$ within a primary sequence that is $60 \%$ homologous. However, all the HBRs on EDN and ECP were located at a similar position and surrounded by an electropositive cavity in their tertiary structures. Peptide containing HBR1 in ECP (NYRWRCKNQNK) had similar LMWH binding activity to the corresponding region of EDN (NYQRRCKNQNK) in FACE analysis [28]. However, mutant MBP-ECPmt1 (R34A/W35A/R36A/K38A) showed only 50\% cellular binding activity as compared to wild type protein at $20 \mu \mathrm{g} / \mathrm{mL}(0.4 \mu \mathrm{M})$ [28]. Here, mutant MBP-EDN-HBR1mt (R35A/R36A/K38A) showed only $20 \%$ at the same concentration. These results indicated that the main cellular binding activity of EDN lies in the primary sequence\#BR1, whereas ECP may interact with cell surface GAGs through not only HBR1 but also other basic residues ( $\mathrm{Arg}^{1}, \mathrm{Arg}^{7}$ and $\left.\mathrm{His}^{64}\right)$ and polar residues $\left(\mathrm{Gln}^{14}\right.$, $\mathrm{Asn}^{39}$ and $\mathrm{Gln}^{40}$ ) surrounded in a basic cavity as prediction model illustrated in a previous study [42].

To identify the key residues of the three HBRs of EDN essential for binding to Beas-2B cells, we generated MBP-EDN single point mutants, in which each basic residue within the HBRs was individually changed into Ala. Among all the single mutants, the cellular binding activities of those with R35A, R36A, K38A, K69A, R114A, R117A, and R118A replacements were significantly reduced to $29 \%, 31 \%, 39 \%, 65 \%, 41 \%, 39 \%$, and $55 \%$, respectively, as compared to the control at protein concentration of $0.2 \mu \mathrm{M}$. Instead, mutations of Lys ${ }^{66}$ and $\mathrm{Arg}^{68}$ resulted in little or insignificant effects (Figure 7 and Table 1). In contrast, K1A, R97A and R132A mutants had no effect (data not shown). These results suggested that the basic residues within HBRs play more important roles in GAG binding and $\mathrm{Arg}^{35}, \mathrm{Arg}^{36}$, and $\mathrm{Arg}^{38}$ in HBR1 and $\mathrm{Arg}^{114}$ and $\mathrm{Arg}^{117}$ in HBR3 are particularly important for the interaction.

Figure 7. Involvement of single basic residues on MBP-EDN in binding to Beas-2B cells. Beas-2B cells were separately incubated with various MBP-EDN with a single point mutation. The level of bound protein was determined by ELISA. (A) R35A, R36A, or K38A; (B) K66A, R68A, or K69A; and (C) R114A, R117A, or R118A. The amount of MBP-EDN bound to Beas-2B cells at $0.8 \mu \mathrm{M}$ was set as $100 \%$ and MBP was used as a negative control. The data shown are mean \pm SD in triplicate assays.

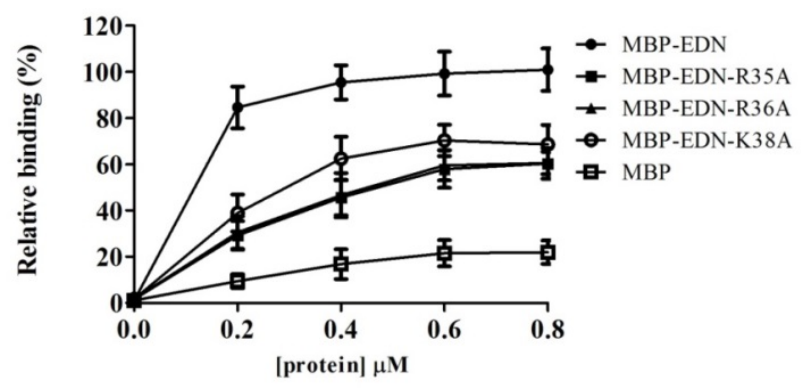

(A)

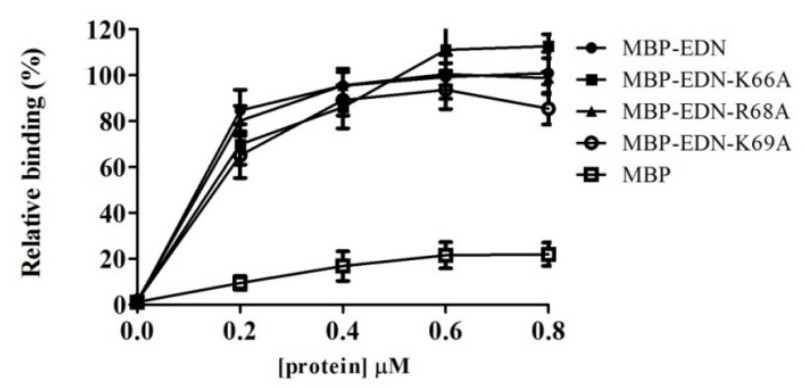

(B) 
Figure 7. Cont.

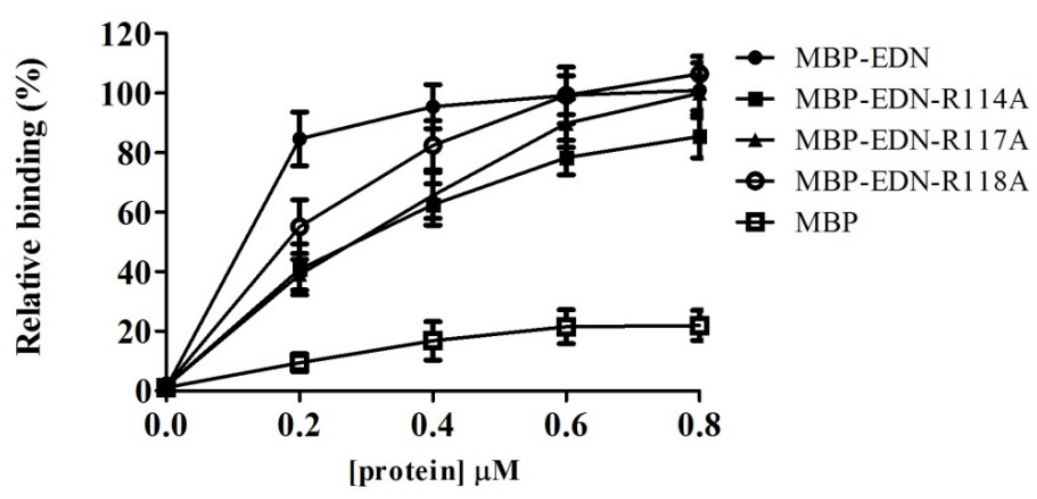

(C)

Table 1. Beas-2B cell binding activity of MBP-EDN wild type and mutants.

\begin{tabular}{cc}
\hline Protein $(\mathbf{0 . 2} \boldsymbol{\mu M})$ & Mean \pm SD $\mathbf{( \% )}$ \\
\hline MBP-EDN & $84.6 \pm 9.0$ \\
R35A & $28.5 \pm 5.8 * * *$ \\
R36A & $31.0 \pm 7.0 * * *$ \\
K38A & $38.9 \pm 8.0 * * *$ \\
K66A & $69.9 \pm 8.8 *$ \\
R68A & $80.1 \pm 6.5$ \\
K69A & $65.1 \pm 9.8 * * *$ \\
R114A & $40.8 \pm 8.5 * * *$ \\
R117A & $39.0 \pm 5.1 * * *$ \\
R118A & $55.1 \pm 9.0 * * *$ \\
MBP-EDN-HBR1mt & $10.9 \pm 6.3 * * *$ \\
MBP-EDN-HBR2mt & $26.2 \pm 8.4 * * *$ \\
MBP-EDN-HBR3mt & $57.8 \pm 7.6 * * *$ \\
MBP & $9.4 \pm 3.0$ \\
\hline
\end{tabular}

The average amount of $0.8 \mu \mathrm{M}$ MBP-EDN bound to Beas-2B cells was set as $100 \%$ binding. ${ }^{*}, p<0.05 ;{ }^{* * *}, p<0.001$.

ECP structure in complex with heparin disaccharide [51] and trisaccharide heparin mimetic [52] have been previously resolved by NMR. The results indicate the crucial role of basic cavity on ECP surface in heparin binding and point out the contribution of residues surrounding the cavity. Other than basic residues, aromatic residue, $\operatorname{Trp}^{35}$, and several polar residues including $\mathrm{Gln}^{14}, \mathrm{Asn}^{39}$, and $\mathrm{Gln}^{40}$ are also involved in these complexes. As for EDN, although MBP-EDN-HBR1mt (R35A/R36A/K38A) showed major contribution in cellular binding, it still possessed $45 \%$ binding activity to LMWH in FACE analysis. In addition, there are six hydrogen bonds in our EDN-heparin hexasaccharide prediction model, revealing that contribution of other aromatic and polar residues such as His, Trp, Asn and Gln should be taken into consideration. 


\section{Experimental Section}

\subsection{Antibodies and Reagents}

Monoclonal mouse anti-MBP was purchased from Santa Cruz (Dallas, TX, USA) and goat anti-mouse horseradish peroxidase (HRP) was purchased from Jackson ImmunoResearch (West Grove, PA, USA). Low molecular weight heparin (LMWH), high molecular weight heparin (HMWH; heparin sodium salt), dermatan sulfate (DS), chondroitin sulfate C (CSC), hyaluronic acid (HA), $N$-acetyl heparin $(N A c H), d e-N$-sulfated heparin $(d e N-\mathrm{SH})$, and $N$-acetyl-de-O-sulfated heparin (NAc-deO-SH) were purchased from Sigma-Aldrich (St. Louis, MO, USA). De-2-O-sulfated heparin (de2O-SH), and de-6-O-sulfated heparin (de6O-SH) were purchased from Neoparin (Alameda, CA, USA). Chemicals were purchased from Sigma-Aldrich (St. Louis, MO, USA) unless otherwise specified.

\subsection{Cells and Cell Culture}

Beas-2B (ATCC number: CRL-9609), a human bronchial epithelial cell line, wild type Chinese hamster ovary (CHO)-K1 (ATCC number: CRL-9618), mutant CHO cell lines pgsD-677 (ATCC number: CRL-2244) and pgsA-745 (ATCC number: CRL-2242) were purchased from American Type Culture Collection (Manassas, VA, USA). Beas-2B cells (ATCC number: CRL-9609) were cultured in RPMI 1640 medium (Sigma-Aldrich, St. Louis, MO, USA) supplemented with heat-inactivated 10\% $(v / v)$ fetal bovine serum (FBS) (Gibco/Invitrogen, Grand Island, NY, USA) and 1\% (v/v) Penicillin, Streptomycin, and Amphotericin (Biosera, Kansas City, MO, USA). CHO cells were cultured in Vitacel Ham's F12K medium (Sigma-Aldrich, St. Louis, MO, USA) supplemented with $10 \%(v / v)$ FBS.

\subsection{Construction, Expression and Purification of MBP-EDN Mutants}

The DNA encoding EDN without the signal sequence was amplified using PCR primers 5'-GAATTCAAACCTCCACAGTTTACC-3' and 5'-TCTAGATTAGATGATTCTATCCAG-3' and cloned into the pMAL-c2G plasmid (New England Biolabs, Hitchin, UK) between the EcoRI and XbaI sites to generate pMAL-c2G-edn. The plasmid was used as a template to generate basic amino acid single mutant including R35A, R36A, K38A, K66A, R68A, K69A, R114A, R117A and R118A using QuikChange site-directed mutagenesis (Stratagene, Santa Clara, CA, USA). In addition, these residues were simultaneously substituted to Ala to generate the following three mutants: MBP-EDN-HBRmt1 (R35A/R36A/K38A), MBP-EDN-HBRmt2 (K66A/R68A/K69A), and MBP-EDN-HBRmt3 (R114A/R117A/R118A) using the same protocol. To express a wild type MBP-EDN and its mutants, the plasmid was used to transform Escherichia coli (E. coli) BL21 (DE3) Gold cells (Stratagene, Santa Clara, CA, USA). Two milliliters of the overnight culture was inoculated in $100 \mathrm{~mL}$ LB broth containing $100 \mu \mathrm{g} / \mathrm{mL}$ carbencillin, and incubated at $37^{\circ} \mathrm{C}$ until $\mathrm{OD}_{600}$ reached 0.4-0.6. IPTG (Ameresco, Solon, $\mathrm{OH}$, USA) was added to a final concentration of $0.5 \mathrm{mM}$, and incubated at $30^{\circ} \mathrm{C}$ for $4 \mathrm{~h}$. After protein induction, the bacteria were harvested by centrifugation for $10 \mathrm{~min}$ at $2900 \times \mathrm{g}$, and the pellet was homogenized by EmulsiFlex-C3 (AVESTIN, Ottawa, ON, Canada). Wild type MBP-EDN and all mutant proteins in the soluble portion of bacterial cell lysates were purified by amylose affinity chromatography (New England Biolab, Hitchin, UK). 


\subsection{Construction, Expression and Purification of Recombinant EDN Containing a C-Terminal} 6His-Tag (EDN-6His)

The edn gene was cloned into the pET23a plasmid (New England Biolabs, Hitchin, UK) between $X b a \mathrm{I}$ and $\mathrm{BamHI}$ to generate pET23a-edn. The expression procedures were same as MBP-EDN but misfolded EDN-6His was accumulated in inclusion bodies. Recombinant EDN-6His was purified by $\mathrm{Ni}^{2+}$ Sepharose ${ }^{\mathrm{TM}}$ (GE Healthcare, Uppsala, Sweden) and refolded and dialyzed as previously described [53].

\subsection{Cell-Based Enzyme-Link Immunosorbent Assay (cELISA)}

Confluent monolayers of Beas-2B or $\mathrm{CHO}$ cells in 96-well plate were incubated with different concentrations of MBP-EDN at $4{ }^{\circ} \mathrm{C}$ for $60 \mathrm{~min}$. The cells were washed with $200 \mu \mathrm{L}$ of ice-cold PBS, and fixed with $2 \%$ paraformaldehyde (PFA)/PBS at $25^{\circ} \mathrm{C}$ for $15 \mathrm{~min}$. Then, $200 \mu \mathrm{L}$ of ice-cold PBS was added to wash the cells prior to blocking with $2 \%$ BSA/PBS at $25{ }^{\circ} \mathrm{C}$ for $90 \mathrm{~min}$. The level of bound MBP-EDN was quantified by ELISA analysis using a mouse monoclonal anti-MBP IgG and a HRP-conjugated goat anti-mouse IgG as the primary and secondary antibody, respectively. After the cells were washed by ice-cold PBS, $50 \mu \mathrm{L}$ of Super Signal ${ }^{\circledR}$ West Pico Chemiluminescent Substrate (Thermo, Waltham, MA, USA) was added and the chemiluminescent intensity was measured by Wallace Vector II (LS55, PerkinElmer, Santa Clara, CA, USA). The amount of MBP-EDN bound to cells without heparin derivatives or GAGs treatment was set to $100 \%$.

\subsection{Fluorescence-Assisted Carbohydrate Electrophoresis (FACE)}

GAGs were labeled with 2-aminoacridone (AMAC) according to the reported procedures [54]. Briefly, $50 \mu \mathrm{g}$ of each GAG was incubated with $40 \mu \mathrm{L}$ of a solution containing $1.25 \mathrm{M} \mathrm{AMAC,} 85 \%$ DMSO, and $15 \%$ acetic acid at $25^{\circ} \mathrm{C}$ for $15 \mathrm{~min}$. To this, $40 \mu \mathrm{L}$ of $1.25 \mathrm{M}$ sodium cyanoborohydride $\left(\mathrm{NaBH}_{3} \mathrm{CN}\right)$ was added, and the mixture was incubated at $37^{\circ} \mathrm{C}$ for $16 \mathrm{~h}$. At the end of the reaction, $720 \mu \mathrm{L}$ of $95 \%$ ice-cold ethanol was added and rested for $15 \mathrm{~min}$ at $-20^{\circ} \mathrm{C}$. The sample was centrifuged at $4{ }^{\circ} \mathrm{C}$ for $5 \mathrm{~min}$ at $14,000 \times \mathrm{g}$. The supernatant was carefully discarded, and the pellet was freeze-dried by ScanVac CoolSafe (LaboGene ${ }^{\mathrm{TM}}$, Lynge, Denmark). The dried pellet was dissolved in sterile deionized water at an appropriate concentration for a measurement. The AMAC-labeled probes thus prepared were stored at $-80^{\circ} \mathrm{C}$ until use.

AMAC-labeled probes and proteins were mixed and incubated at $25^{\circ} \mathrm{C}$ for $15 \mathrm{~min}$. The mixture was loaded onto a $1 \%$ agarose gel plate, and electrophoresed for $20 \mathrm{~min}$ in a buffer containing $40 \mathrm{mM}$ Tris-acetic acid, $1 \mathrm{mM}$ EDTA, $\mathrm{pH}$ 8.0. The AMAC labeled probe was detected under UV light and the gel was scanned by QUANTUM-ST4 (Vilber Lourmat, Eberhardzell, Germany).

\subsection{Binding Competition Assay}

For competition assay, monolayers of Beas-2B cells in 96-well plates were pre-incubated with serially diluted heparin derivatives or GAGs in serum-free RPMI 1640 medium at $4{ }^{\circ} \mathrm{C}$ for $30 \mathrm{~min}$. To the samples, MBP-EDN was added, and incubated at $4{ }^{\circ} \mathrm{C}$ for $60 \mathrm{~min}$. Bound MBP-EDN was measured as described above. 


\subsection{Computer Modeling of EDN-Heparin Oligosaccharide Complex}

The structure of EDN was taken from PDB database (PDB entry 1HI2) [55], and energy minimized with the GROMOS 96 force field. In silico docking experiments were performed using AutoDock Vina software (AutoDock, La Jolla, CA, USA) [56]. Preliminary docking runs were performed with comprising three of ${ }^{1} \mathrm{C}_{4}$-IdoA(2S)-GlcNS(6S). In order to find preferred side chain conformations, all basic residues in three HBRs of EDN were set to be flexible in computation. Global search was performed in the grid box with a dimension of $60 \times 60 \times 60$ angstroms that covered the entire protein. For computer simulation, we chose heparin hexasaccharide with chair forms of IdoAs as a ligand and used predetermined coordinates for the side chains of basic residues within HBRs.

\subsection{Statistical Analysis}

Statistical analysis was performed using GraphPad Prism 5 (GraphPad Software, La Jolla, CA, USA). All data are shown in mean \pm standard deviation (SD). Statistical significance between a set of data was determined by unpaired two-tailed Student's $t$-test.

\section{Conclusions}

In conclusion, membrane GAGs, especially HS and DS, were essential for EDN interaction with Beas-2B cells. The Sulfo group of heparin, predominantly $2-O$ - or 6-O-sulfo group, is an obligatory factor for EDN interaction to heparin and Beas-2B cells. A combination of in silico bioinformatics analyses and in vitro functional assays has successfully identified that basic residues $\mathrm{Arg}^{35}, \mathrm{Arg}^{36}$, and $\mathrm{Arg}^{38}$ in HBR1, and $\mathrm{Arg}^{114}$ and $\mathrm{Arg}^{117}$ in HBR3 of EDN play a critical role in GAG binding. These results provide an insight into the molecular interaction of EDN with soluble heparin and bronchial epithelial cells which may have biomedical implications for the physiological functions of eosinophil RNases.

\section{Acknowledgments}

This work was funded by National Science Council, R.O.C. grants (grant numbers NSC102-2325-B-007-002- and NSC102-2622-B-007-001-CC1) and National Tsing Hua University (NTHU100N7051E1 and NTHU101N2051E1). Ta-Jen Hung was supported by Initiative Research Cooperation among Top Universities between UK and Taiwan (grant number NSC99-2911-I-007-035) and Graduate Students Study Abroad Program of National Science Council of Taiwan (grant number NSC100-2917-I-007-008). Chien-Jung Chen and Ping-Hsueh Kuo were awarded a scholarship sponsored by Shen's Culture and Education Foundation. The authors are grateful to Wen-Chi Cheng (Institute of Molecular and Cellular Biology, National Tsing Hua University, Hsinchu, Taiwan) and Chao-sheng Cheng (Institute of Bioinformatics and Structural Biology, National Tsing Hua University, Hsinchu, Taiwan) for proofreading this manuscript and offering critical comments.

\section{Conflicts of Interest}

The authors declare no conflict of interest 


\section{References}

1. Gleich, G.J.; Adolphson, C.R. The eosinophilic leukocyte: Structure and function. Adv. Immunol. 1986, 39, 177-253.

2. Rosenberg, H.F.; Tenen, D.G.; Ackerman, S.J. Molecular cloning of the human eosinophil-derived neurotoxin: A member of the ribonuclease gene family. Proc. Natl. Acad. Sci. USA 1989, 86, 4460-4464.

3. Gleich, G.J. Eosinophils, basophils, and mast cells. J. Allergy Clin. Immunol. 1989, 84, 1024-1027.

4. Futami, J.; Tsushima, Y.; Murato, Y.; Tada, H.; Sasaki, J.; Seno, M.; Yamada, H. Tissue-specific expression of pancreatic-type rnases and rnase inhibitor in humans. DNA Cell Biol. 1997, 16, 413-419.

5. Durack, D.T.; Sumi, S.M.; Klebanoff, S.J. Neurotoxicity of human eosinophils. Proc. Natl. Acad. Sci. USA 1979, 76, 1443-1447.

6. Durack, D.T.; Ackerman, S.J.; Loegering, D.A.; Gleich, G.J. Purification of human eosinophil-derived neurotoxin. Proc. Natl. Acad. Sci. USA 1981, 78, 5165-5169.

7. Fredens, K.; Dahl, R.; Venge, P. The gordon phenomenon induced by the eosinophil cationic protein and eosinophil protein x. J. Allergy Clin. Immunol. 1982, 70, 361-366.

8. Domachowske, J.B.; Dyer, K.D.; Bonville, C.A.; Rosenberg, H.F. Recombinant human eosinophil-derived neurotoxin/rnase 2 functions as an effective antiviral agent against respiratory syncytial virus. J. Infect. Dis. 1998, 177, 1458-1464.

9. Lee-Huang, S.; Huang, P.L.; Sun, Y.; Kung, H.F.; Blithe, D.L.; Chen, H.C. Lysozyme and rnases as anti-hiv components in beta-core preparations of human chorionic gonadotropin. Proc. Natl. Acad. Sci. USA 1999, 96, 2678-2681.

10. Rugeles, M.T.; Trubey, C.M.; Bedoya, V.I.; Pinto, L.A.; Oppenheim, J.J.; Rybak, S.M.; Shearer, G.M. Ribonuclease is partly responsible for the hiv-1 inhibitory effect activated by hla alloantigen recognition. AIDS 2003, 17, 481-486.

11. Kephart, G.M.; Alexander, J.A.; Arora, A.S.; Romero, Y.; Smyrk, T.C.; Talley, N.J.; Kita, H. Marked deposition of eosinophil-derived neurotoxin in adult patients with eosinophilic esophagitis. Am. J. Gastroenterol. 2010, 105, 298-307.

12. Liu, G.T.; Hwang, C.S.; Hsieh, C.H.; Lu, C.H.; Chang, S.L.; Lee, J.C.; Huang, C.F.; Chang, H.T. Eosinophil-derived neurotoxin is elevated in patients with amyotrophic lateral sclerosis. Mediators Inflamm. 2013, 2013, 421389.

13. Yang, D.; Rosenberg, H.F.; Chen, Q.; Dyer, K.D.; Kurosaka, K.; Oppenheim, J.J. Eosinophil-derived neurotoxin (edn), an antimicrobial protein with chemotactic activities for dendritic cells. Blood 2003, 102, 3396-3403.

14. Yang, D.; Chen, Q.; Rosenberg, H.F.; Rybak, S.M.; Newton, D.L.; Wang, Z.Y.; Fu, Q.; Tchernev, V.T.; Wang, M.; Schweitzer, B.; et al. Human ribonuclease a superfamily members, eosinophil-derived neurotoxin and pancreatic ribonuclease, induce dendritic cell maturation and activation. J. Immunol. 2004, 173, 6134-6142.

15. Yang, D.; Chen, Q.; Su, S.B.; Zhang, P.; Kurosaka, K.; Caspi, R.R.; Michalek, S.M.; Rosenberg, H.F.; Zhang, N.; Oppenheim, J.J. Eosinophil-derived neurotoxin acts as an alarmin to 
activate the tlr2-myd88 signal pathway in dendritic cells and enhances th2 immune responses. J. Exp. Med. 2008, 205, 79-90.

16. Mayer, A.K.; Muehmer, M.; Mages, J.; Gueinzius, K.; Hess, C.; Heeg, K.; Bals, R.; Lang, R.; Dalpke, A.H. Differential recognition of tlr-dependent microbial ligands in human bronchial epithelial cells. J. Immunol. 2007, 178, 3134-3142.

17. Jack, C.S.; Arbour, N.; Manusow, J.; Montgrain, V.; Blain, M.; McCrea, E.; Shapiro, A.; Antel, J.P. Tlr signaling tailors innate immune responses in human microglia and astrocytes. J. Immunol. 2005, $175,4320-4330$.

18. Zarember, K.A.; Godowski, P.J. Tissue expression of human toll-like receptors and differential regulation of toll-like receptor mrnas in leukocytes in response to microbes, their products, and cytokines. J. Immunol. 2002, 168, 554-561.

19. Hung, S.C.; Lu, X.A.; Lee, J.C.; Chang, M.D.; Fang, S.L.; Fan, T.C.; Zulueta, M.M.; Zhong, Y.Q. Synthesis of heparin oligosaccharides and their interaction with eosinophil-derived neurotoxin. Org. Biomol. Chem. 2012, 10, 760-772.

20. Gleich, G.J.; Loegering, D.A.; Bell, M.P.; Checkel, J.L.; Ackerman, S.J.; McKean, D.J. Biochemical and functional similarities between human eosinophil-derived neurotoxin and eosinophil cationic protein: Homology with ribonuclease. Proc. Natl. Acad. Sci. USA 1986, 83, 3146-3150.

21. Prydz, K.; Dalen, K.T. Synthesis and sorting of proteoglycans. J. Cell Sci. 2000, 113, 193-205.

22. Capila, I.; Linhardt, R.J. Heparin-protein interactions. Angew Chem. Int. Ed. Engl. 2002, 41, 391-412.

23. Linhardt, R.J.; Ampofo, S.A.; Fareed, J.; Hoppensteadt, D.; Mulliken, J.B.; Folkman, J. Isolation and characterization of human heparin. Biochemistry 1992, 31, 12441-12445.

24. Sasisekharan, R.; Raman, R.; Prabhakar, V. Glycomics approach to structure-function relationships of glycosaminoglycans. Annu. Rev. Biomed. Eng. 2006, 8, 181-231.

25. Mulloy, B.; Rider, C.C. Cytokines and proteoglycans: An introductory overview. Biochem. Soc. Trans. 2006, 34, 409-413.

26. Munoz, E.M.; Linhardt, R.J. Heparin-binding domains in vascular biology. Arterioscler. Thromb. Vasc. Biol. 2004, 24, 1549-1557.

27. Cardin, A.D.; Weintraub, H.J. Molecular modeling of protein-glycosaminoglycan interactions. Arteriosclerosis 1989, 9, 21-32.

28. Fan, T.C.; Fang, S.L.; Hwang, C.S.; Hsu, C.Y.; Lu, X.A.; Hung, S.C.; Lin, S.C.; Chang, M.D. Characterization of molecular interactions between eosinophil cationic protein and heparin. J. Biol. Chem. 2008, 283, 25468-25474.

29. Fang, S.L.; Fan, T.C.; Fu, H.W.; Chen, C.J.; Hwang, C.S.; Hung, T.J.; Lin, L.Y.; Chang, M.D. A novel cell-penetrating peptide derived from human eosinophil cationic protein. PLoS One 2013, 8, e57318.

30. Newton, D.L.; Nicholls, P.J.; Rybak, S.M.; Youle, R.J. Expression and characterization of recombinant human eosinophil-derived neurotoxin and eosinophil-derived neurotoxin-anti-transferrin receptor sfv. J. Biol. Chem. 1994, 269, 26739-26745.

31. Fan, T.C.; Chang, H.T.; Chen, I.W.; Wang, H.Y.; Chang, M.D. A heparan sulfate-facilitated and raft-dependent macropinocytosis of eosinophil cationic protein. Traffic 2007, 8, 1778-1795. 
32. Watterson, D.; Kobe, B.; Young, P.R. Residues in domain iii of the dengue virus envelope glycoprotein involved in cell-surface glycosaminoglycan binding. J. Gen. Virol. 2012, 93, 72-82.

33. Puck, T.T.; Kao, F.T. Genetics of somatic mammalian cells, vi, use of an antimetabolite in analysis of gene multiplicity. Proc. Natl. Acad. Sci. USA 1968, 60, 561-568.

34. Lidholt, K.; Weinke, J.L.; Kiser, C.S.; Lugemwa, F.N.; Bame, K.J.; Cheifetz, S.; Massague, J.; Lindahl, U.; Esko, J.D. A single mutation affects both $\mathrm{N}$-acetylglucosaminyltransferase and glucuronosyltransferase activities in a chinese hamster ovary cell mutant defective in heparan sulfate biosynthesis. Proc. Natl. Acad. Sci. USA 1992, 89, 2267-2271.

35. Esko, J.D. Animal cell mutants defective in heparan sulfate polymerization. Adv. Exp. Med. Biol. 1992, 313, 97-106.

36. Trowbridge, J.M.; Gallo, R.L. Dermatan sulfate: New functions from an old glycosaminoglycan. Glycobiology 2002, 12, 117R-125R.

37. Hamazaki, H. $\mathrm{Ca}^{2+}$-mediated association of human serum amyloid $\mathrm{p}$ component with heparan sulfate and dermatan sulfate. J. Biol. Chem. 1987, 262, 1456-1460.

38. Catlow, K.R.; Deakin, J.A.; Wei, Z.; Delehedde, M.; Fernig, D.G.; Gherardi, E.; Gallagher, J.T.; Pavao, M.S.; Lyon, M. Interactions of hepatocyte growth factor/scatter factor with various glycosaminoglycans reveal an important interplay between the presence of iduronate and sulfate density. J. Biol. Chem. 2008, 283, 5235-5248.

39. Hallak, L.K.; Collins, P.L.; Knudson, W.; Peeples, M.E. Iduronic acid-containing glycosaminoglycans on target cells are required for efficient respiratory syncytial virus infection. Virology 2000, 271, 264-275.

40. Irie, M. structures and functions of ribonucleases. Yakugaku Zasshi 1997, 117, 561-582.

41. Rosenberg, H.F. Rnase a ribonucleases and host defense: An evolving story. J. Leukoc. Biol. 2008, $83,1079-1087$.

42. Torrent, M.; Nogues, M.V.; Boix, E. Eosinophil cationic protein (ecp) can bind heparin and other glycosaminoglycans through its rnase active site. J. Mol. Recognit. 2011, 24, 90-100.

43. Ye, S.; Luo, Y.; Lu, W.; Jones, R.B.; Linhardt, R.J.; Capila, I.; Toida, T.; Kan, M.; Pelletier, H.; McKeehan, W.L. Structural basis for interaction of fgf-1, fgf-2, and fgf-7 with different heparan sulfate motifs. Biochemistry 2001, 40, 14429-14439.

44. Copeland, R.; Balasubramaniam, A.; Tiwari, V.; Zhang, F.; Bridges, A.; Linhardt, R.J.; Shukla, D.; $\mathrm{Liu}$, J. Using a 3-O-sulfated heparin octasaccharide to inhibit the entry of herpes simplex virus type 1. Biochemistry 2008, 47, 5774-5783.

45. Seki, Y.; Mizukura, M.; Ichimiya, T.; Suda, Y.; Nishihara, S.; Masuda, M.; Takase-Yoden, S. O-sulfate groups of heparin are critical for inhibition of ecotropic murine leukemia virus infection by heparin. Virology 2012, 424, 56-66.

46. Guimond, S.; Maccarana, M.; Olwin, B.B.; Lindahl, U.; Rapraeger, A.C. Activating and inhibitory heparin sequences for fgf-2 (basic fgf). Distinct requirements for fgf-1, fgf-2, and fgf-4. J. Biol. Chem. 1993, 268, 23906-23914.

47. Ishihara, M.; Kariya, Y.; Kikuchi, H.; Minamisawa, T.; Yoshida, K. Importance of 2-O-sulfate groups of uronate residues in heparin for activation of fgf-1 and fgf-2. J. Biochem. 1997, 121, 345-349. 
48. Sikriwal, D.; Seth, D.; Parveen, S.; Malik, A.; Broor, S.; Batra, J.K. An insertion in loop 17 of human eosinophil derived neurotoxin is crucial for its antiviral activity. J. cell. Biochem. 2012, 113, 3104-3112.

49. Sakurai, H.; Williamson, R.A.; Crowe, J.E.; Beeler, J.A.; Poignard, P.; Bastidas, R.B.; Chanock, R.M.; Burton, D.R. Human antibody responses to mature and immature forms of viral envelope in respiratory syncytial virus infection: Significance for subunit vaccines. J. Virol. 1999, 73, 2956-2962.

50. Lien, P.C.; Kuo, P.H.; Chen, C.J.; Chang, H.H.; Fang, S.L.; Wu, W.S.; Lai, Y.K.; Pai, T.W.; Chang, M.D. In silico prediction and in vitro characterization of multifunctional human rnase3. BioMed. Res. Int. 2013, 2013, 170398.

51. Garcia-Mayoral, M.F.; Moussaoui, M.; de la Torre, B.G.; Andreu, D.; Boix, E.; Nogues, M.V.; Rico, M.; Laurents, D.V.; Bruix, M. Nmr structural determinants of eosinophil cationic protein binding to membrane and heparin mimetics. Biophys. J. 2010, 98, 2702-2711.

52. Garcia-Mayoral, M.F.; Canales, A.; Diaz, D.; Lopez-Prados, J.; Moussaoui, M.; de Paz, J.L.; Angulo, J.; Nieto, P.M.; Jimenez-Barbero, J.; Boix, E.; et al. Insights into the glycosaminoglycan-mediated cytotoxic mechanism of eosinophil cationic protein revealed by nmr. ACS Chem. Biol. 2013, 8, 144-151.

53. Boix, E.; Nikolovski, Z.; Moiseyev, G.P.; Rosenberg, H.F.; Cuchillo, C.M.; Nogues, M.V. Kinetic and product distribution analysis of human eosinophil cationic protein indicates a subsite arrangement that favors exonuclease-type activity. J. Biol. Chem. 1999, 274, 15605-15614.

54. Calabro, A.; Benavides, M.; Tammi, M.; Hascall, V.C.; Midura, R.J. Microanalysis of enzyme digests of hyaluronan and chondroitin/dermatan sulfate by fluorophore-assisted carbohydrate electrophoresis (face). Glycobiology 2000, 10, 273-281.

55. Leonidas, D.D.; Boix, E.; Prill, R.; Suzuki, M.; Turton, R.; Minson, K.; Swaminathan, G.J.; Youle, R.J.; Acharya, K.R. Mapping the ribonucleolytic active site of eosinophil-derived neurotoxin (edn). High resolution crystal structures of edn complexes with adenylic nucleotide inhibitors. J. Biol. Chem. 2001, 276, 15009-15017.

56. Trott, O.; Olson, A.J. Autodock vina: Improving the speed and accuracy of docking with a new scoring function, efficient optimization, and multithreading. J. Comput. Chem. 2010, 31, 455-461.

(C) 2013 by the authors; licensee MDPI, Basel, Switzerland. This article is an open access article distributed under the terms and conditions of the Creative Commons Attribution license (http://creativecommons.org/licenses/by/3.0/). 